\title{
Smoking behavior among Hispanic adults with diabetes on the United States-Mexico border: a public health opportunity
}

\author{
Pamela Stoddard, ${ }^{1}$ Guozhong $\mathrm{He},{ }^{2,3}$ and Dean Schillinger, ${ }^{2,3,4,5}$
}

ABSTRACT Objective. To examine the prevalence of smoking behaviors among adults with diabetes on the United States-Mexico border, to compare these behaviors in U.S. Hispanics and Mexicans with diabetes, and to identify explanations for group differences.

Methods. Data came from the U.S.-Mexico Border Diabetes Prevention and Control Project survey (2001-2002), a stratified, multistage sample representative of the border population. The analytic sample included adults from all racial and ethnic backgrounds with diabetes $(\mathrm{n}=665)$, including 333 Mexicans and 268 U.S. Hispanics. Smoking behaviors were based on self-reports. Age- and gender-specific prevalence of smoking behavior was estimated and logistic regression was used for mediation analysis of group differences.

Results. One in five adults with diabetes $(20.1 \%)$ in the region was a current smoker. Prevalence was higher among Mexicans (26.2\%) than U.S. Hispanics (10.1\%, P = 0.003); differences were not explained by sociodemographic or healthcare-related characteristics (odds ratio [OR] 3.86, 95\% confidence interval [CI] 1.50-9.91, P = 0.004). Younger Mexicans with diabetes (< 55 years) were four times more likely to smoke than younger U.S. Hispanics (32.1\% versus $8.1 \%, \mathrm{P}<0.001)$ and Mexican men with diabetes were more than twice as likely to smoke as U.S. Hispanic men (38.9\% versus $15.8 \%, \mathrm{P}=0.003$ ). Among adults with diabetes with a smoking history, $52.5 \%$ were former smokers; U.S. Hispanics were more likely to be former smokers than Mexicans with diabetes $(62.6 \%$ versus $27.5 \%, \mathrm{P}=0.001)$. A marginally significant difference remained after adjusting for potential mediators (OR 0.42, 95\% CI 0.17-1.08, P = 0.074).

Conclusions. Smoking interventions should focus on Mexicans with diabetes in the border region, especially younger adults and men. Identifying sources of differences in smoking behaviors among border groups with diabetes may further inform intervention.

Key words Tobacco; smoking; smoking cessation; border health; Hispanic Americans; Mexico.

1 Philip R. Lee Institute for Health Policy Studies, University of California, San Francisco, San Francisco, California, United States of America.

2 Institute on Health and Aging, University of California, San Francisco, San Francisco, California, United States of America.

3 California Diabetes Program, California Department of Public Health, Sacramento, California, United States of America. Send correspondence to Guozhong He, ghe@dhs.ca.gov.

4 Department of General Internal Medicine, University of California, San Francisco, San Francisco, California, United States of America.
Tobacco use, the leading cause of preventable death worldwide, is estimated to kill 5 million people each year (1). Smoking represents a particular health hazard

\footnotetext{
5 Center for Vulnerable Populations and San Francisco General Hospital, University of California, San Francisco, San Francisco, California, United States of America.
}

to adults with diabetes. It has been shown to exacerbate hyperglycemia and insulin resistance, accelerate the development of microvascular complications like nephropathy and end-stage renal disease, and heighten the risk of cardiovascular disease and related death, which are already significantly elevated among adults with diabetes (2-8). 
Understanding smoking behaviors in adults with diabetes is thus essential to efforts to improve population health. This is particularly true in areas where diabetes prevalence is high, such as the United States-Mexico border region. In 2001-2002, 1.2 of 7.5 million adults in the region $(15.7 \%)$ had diabetes $(9)$. Diabetes prevalence in U.S. and Mexico border populations was substantially higher than national estimates from either country $(10,11)$. This study examined smoking behaviors in the border population with diabetes as a whole as well as differences among Hispanics with diabetes living on either side of the border. The investigation used data from the U.S.-Mexico Border Diabetes Prevention and Control Project. The project has taken the unique view of the border region as a single epidemiologic unit and was undertaken to coordinate efforts to decrease the impact of diabetes across the region.

Most individuals living in the region are Hispanic. However, smoking behaviors are likely to vary in the Hispanic population on either side of the border, given differences in sociodemographic characteristics, access to healthcare, and tobacco policies and prevention and cessation programs (9, 12-17). The U.S.Mexico Border Diabetes Prevention and Control Project survey provides an unusual opportunity to compare smoking behaviors among Hispanic adults with diabetes in the U.S. and Mexican border populations. A better understanding of smoking behaviors across border subgroups with diabetes may help to target intervention and allocate resources.

Estimates from national surveys of smoking prevalence among all adults with diabetes in each country suggest that levels in the Mexican population exceed those in the U.S. Hispanic population $(18,19)$. For this reason, it was expected that prevalence of current smoking in the border region among Mexicans with diabetes would be higher than that among U.S. Hispanics with diabetes. Along the same lines, it was anticipated that prevalence of former smoking among adults with diabetes with a smoking history would be higher among U.S. Hispanics with diabetes than their Mexican counterparts. Given a lack of empirical research on mean number of cigarettes smoked per day among current smokers in these populations, there were no a priori assumptions made concerning differences in this outcome between border groups. It was hypothesized that differences between the two border groups in current and former smoking would be partially explained by sociodemographic characteristics and healthcare access (20-22). However, some gap was expected to remain, given that it was not possible to include indicators of the regulatory environment surrounding smoking in the two countries $(12-17,23,24)$ or measures of programmatic support for smoking prevention and cessation.

The study further examined whether differences in current and former smoking in the two border populations depended on gender or diabetes diagnosis. Gender norms sanctioning smoking among Hispanic women may extend to those with diabetes (25-27). These norms may be weaker among U.S. Hispanic than Mexican women on the U.S. border due to acculturation (25-27); therefore, there may have been a greater gender gap in current smoking in the Mexican versus U.S. Hispanic border population with diabetes. There was no expectation of gender variation for former smoking, given that gender norms are less likely to factor in to the decision to quit smoking once it has been initiated. Differences in smoking behaviors by diabetes diagnosis in U.S. Hispanics versus Mexicans with diabetes were expected due to variation in the capacity of the U.S. and Mexican healthcare systems to provide smoking prevention and cessation counseling at and after diabetes diagnosis $(21,28)$.

In sum, the objectives of this study were to examine the prevalence of smoking behaviors in the border region overall and to identify differences in these behaviors in U.S. Hispanic versus Mexican adults with diabetes, to determine whether disparities were explained by sociodemographic and healthcare-related characteristics, and to investigate variation in smoking behaviors by gender and diabetes diagnosis between the two groups.

\section{MATERIALS AND METHODS}

\section{Data source}

An observational cross-sectional study was conducted with data from the U.S.-Mexico Border Diabetes Prevention and Control Project survey. The survey was representative of the noninstitution- alized adult population living in counties contiguous to the U.S.-Mexico border in 2001-2002 in six Mexico border states (Baja California, Sonora, Chihuahua, Coahuila, Nuevo Leon, and Tamaulipas) and four U.S. border states (California, Arizona, New Mexico, and Texas) (29). The sample included 44 border communities (28 in Mexico and 16 in the United States). The survey employed a stratified, multistage probability design and oversampled Hispanic adults on the U.S. border (29). One adult aged 18 years or older was randomly sampled in selected households. The response rate was $93.5 \%$ (30).

Each sampled adult was asked to participate in a face-to-face interview and a health assessment. The health assessment included collecting a fasting blood sample to evaluate diabetes status (29). In the United States, participants were interviewed in language of preference (English or Spanish).

The analytic sample for current smoking was restricted to adults with diabetes. Diabetes was defined as having a fasting plasma glucose level of $\geq 126$ $\mathrm{mg} / \mathrm{dL}$ of blood or a self-reported diabetes diagnosis from a healthcare professional (other than diagnosis only during pregnancy). The sample for estimates of current smoking for the border population as a whole included 665 adults (including those from non-Hispanic racial and ethnic backgrounds in the United States). For comparison of current smoking between Hispanic border groups, the sample included 268 U.S. Hispanic adults and 333 Mexican adults. Analysis of mean cigarettes per day was limited to current smokers with diabetes with no missing data on this variable (125 adults overall, including non-Hispanic smokers, and 33 U.S. Hispanics and 72 Mexicans). For analysis of former smoking among adults with a smoking history (see definition below), the sample included 257 adults with diabetes in the overall regional population, including 89 U.S. Hispanic and 123 Mexican adults. All samples excluded adults with missing data on any study variable (less than $2 \%$ of any single variable).

\section{Variable definition}

Several variables were defined for smoking behaviors: current smoking (among all adults with diabetes), mean number of cigarettes smoked per day 
(among current smokers), and former smoking (among all adults with diabetes as well as only those adults with a smoking history). For the first variable, all adults were defined as either current smokers or nonsmokers. Current smokers were defined as those who reported smoking every day or some days, among individuals who had smoked at least 100 cigarettes in their entire lives. Nonsmokers were those who had smoked fewer than 100 cigarettes in their lifetimes as well as former smokers (see definition below). A variable for mean cigarettes smoked per day in the past 30 days was defined for current smokers. For the analysis of former smoking, former smokers were defined as those who had smoked at least 100 cigarettes in their lifetimes but who did not currently smoke. Sample size limitations precluded an analysis of quit attempts in a recent period among adult smokers with diabetes. Analysis of former smoking was intended to provide a sense of cessation among ever-smokers with diabetes in the region in general rather than after the development of diabetes. A sensitivity analysis was conducted in which former smokers were defined as those who had ceased smoking more than 6 months before the survey (i.e., successful quitters, a subset of all former smokers who had ceased smoking at any time before the survey) (31).

U.S. Hispanics and Mexicans were defined based on a code indicating country of residence. U.S. Hispanics were categorized as those in the U.S. border population self-reporting Hispanic ethnicity. Of the sample of U.S. Hispanics with diabetes, $38.8 \%$ were born in the United States and $61.1 \%$ were born outside the United States. U.S.-born Hispanics were not asked about their country of origin; however, the vast majority was likely to be of Mexican descent (32). Slightly more than half of U.S.-born Hispanics indicated English as the language of preference for the survey interview (51.1\%), whereas almost all foreign-born Hispanics living on the U.S. border indicated a preference for Spanish (95.6\%). Sample size was insufficient to conduct multivariate analyses for U.S. Hispanics by nativity (i.e., born in or outside the United States), language of preference for the interview, or other proxies for acculturation. However, in preliminary analysis, no significant differences were found in smoking behaviors for His- panic immigrant versus U.S.-born Hispanic adults with diabetes.

Sociodemographic variables included age (defined as $<55$ years or $\geq 55$ years), gender, education (less than high school or high school or more), and marital status (married or in a consensual union versus divorced, widowed, or never married). Three variables were included to indicate healthcare access, including a self-reported diabetes diagnosis by a healthcare professional, health insurance, and whether an individual had visited a doctor or other healthcare worker in the 12 months preceding the survey.

\section{Analysis}

Descriptive statistics were calculated for all independent variables by border population with diabetes. Prevalence of smoking behaviors was also estimated for all adults with diabetes in the region as a whole and in the two Hispanic border groups. In addition, age- and gender-specific prevalence for each smoking behavior by border population was estimated. Group differences were tested via chi-squared tests and least-squares regression. All estimates were weighted using weights provided by the U.S.Mexico Border Diabetes Prevention and Control Project (29).

Logistic regression was used to examine variation in current smoking among all adults with diabetes and former smoking among adults with diabetes with a smoking history for Mexicans versus U.S. Hispanics. Because the difference between the two border populations in the mean number of cigarettes smoked per day was not significant (see below), multivariate models were not estimated for this outcome. In the first model, unadjusted odds ratios (ORs) for each behavior by border population were provided, with U.S. Hispanics serving as the reference group. Separate logistic regressions were then estimated, adjusting for each individual sociodemographic or healthcare-related covariate. The final model simultaneously adjusted for all sociodemographic and healthcarerelated covariates. Results are presented only for the unadjusted and full models. Contributions of individual variables to group differences are discussed in the text. Variation in the association between border population and each outcome by gender and diabetes diagnosis was ana- lyzed by including an interaction term between these variables in the final model. Predicted probabilities for significant interaction terms were generated to assist with interpretation. Results from interactions and predicted probabilities are reported in the text. All analyses were conducted using Stata 11.0; survey estimation commands were used to adjust for the complex sampling scheme in the survey (33).

\section{RESULTS}

As shown in Table 1, U.S. Hispanics with diabetes were older than Mexicans, on average (52.1 versus 46.8 years), more likely to have a high school education or more (50.3\% versus $21.6 \%)$, less likely to be married or in a consensual union (60.9\% versus $79.7 \%)$, and more likely to be diagnosed $(74.8 \%$ versus $60.8 \%)$; only differences for education $(P<0.001)$ and diagnosis $(P=0.05)$ were statistically or marginally significant. U.S. Hispanics were significantly more likely to be age 55 years or older than Mexicans with diabetes $(P=0.03)$. They were less likely to be insured than Mexicans with diabetes (66.6\% versus $75.2 \%)$ but more likely to have visited a healthcare professional in the past 12 months (84.9\% versus $73.1 \%$ ), although only the latter difference was close to significant $(P=0.071)$.

Approximately one in five adults with diabetes in the border region was a current $(20.1 \%)$ or former smoker $(22.8 \%)$ (Table 2). Smokers with diabetes consumed 14.1 cigarettes per day on average. Approximately half of border adults with diabetes with a smoking history (52.5\%) had quit smoking.

Mexicans with diabetes were more than twice as likely to be current smokers as U.S. Hispanics (26.2\% and 10.1\%, respectively, $P=0.003$ ) (Table 2 ). Among current smokers, the mean number of cigarettes smoked per day was similar for the two groups (12.3 for Mexicans versus 11.7 for U.S. Hispanics, $P=0.892$ ). Being a former smoker was more common among U.S. Hispanics than among Mexicans with diabetes, both in terms of all adults $(16.7 \%$ and $10.0 \%$, respectively, $P=0.001)$ and among those with a smoking history $(62.6 \%$ and $27.5 \%$, respectively, $P=0.001$ ).

Age-specific rates suggest that being a current smoker was less common with older age in the border population with diabetes as a whole and among Mexi- 
TABLE 1. Characteristics of U.S. Hispanic and Mexican adults with diabetes residing on the U.S.-Mexico border, U.S.-Mexico Border Diabetes Prevention and Control Project survey, 2001-2002 $(n=665)^{\mathrm{a}}$

\begin{tabular}{|c|c|c|c|c|c|c|c|}
\hline \multirow[b]{2}{*}{ Characteristic } & \multicolumn{2}{|c|}{$\begin{array}{l}\text { Border }^{\mathrm{b}} \\
(n=665)\end{array}$} & \multicolumn{2}{|c|}{$\begin{array}{l}\text { Mexican } \\
(n=333)\end{array}$} & \multicolumn{2}{|c|}{$\begin{array}{l}\text { U.S. Hispanic } \\
\quad(n=268)\end{array}$} & \multirow[b]{2}{*}{$P^{c}$} \\
\hline & $\%$ & $\mathrm{SE}^{\mathrm{d}}$ & $\%$ & SE & $\%$ & SE & \\
\hline \multicolumn{8}{|l|}{ Sociodemographics } \\
\hline Age, years (mean) & 53.0 & 1.7 & 46.8 & 1.3 & 52.1 & 4.1 & 0.214 \\
\hline$\geq 55$ years of age & 50.5 & 4.8 & 33.9 & 3.9 & 52.1 & 7.6 & 0.032 \\
\hline Men & 53.1 & 4.6 & 50.4 & 4.5 & 45.2 & 7.8 & 0.564 \\
\hline High school education or more & 50.1 & 4.7 & 21.6 & 3.7 & 50.3 & 7.4 & $<0.001$ \\
\hline Married or in a consensual union ${ }^{e}$ & 67.9 & 4.2 & 79.7 & 4.1 & 60.9 & 8.3 & 0.328 \\
\hline \multicolumn{8}{|l|}{ Healthcare and health information } \\
\hline Diagnosed with diabetes & 76.4 & 3.0 & 60.8 & 4.4 & 74.8 & 5.3 & 0.050 \\
\hline Has health insurance & 80.3 & 2.9 & 75.2 & 4.4 & 66.6 & 6.2 & 0.254 \\
\hline \multicolumn{8}{|l|}{ Visited a healthcare professional in } \\
\hline
\end{tabular}

a Estimates are weighted using weights provided by the U.S.-Mexico Border Diabetes Prevention and Control Project (29).

${ }^{b}$ Includes all adults with diabetes on the U.S.-Mexico border, including Mexicans, U.S. Hispanics, non-Hispanic whites, and U.S. adults of other racial or ethnic background.

${ }^{c} P$ value from chi-squared tests (percentages) and least-squares regression (means) for differences in characteristics for U.S. Hispanic versus Mexican adults.

¿SE: standard error.

eVersus divorced, widowed, or never married.

cans but more common with older age among U.S. Hispanics. However, only the difference for Mexicans was significant $(P=0.008)$. Younger Mexicans with diabetes (18-54 years of age) were four times more likely to be current smokers than U.S. Hispanics in the same age group $(32.1 \%$ and $8.1 \%$, respectively, $P<0.001)$. Differences in cigarette consumption per day among older versus younger smokers with diabetes within border populations were not statistically significant.

Being a former smoker was significantly or marginally significantly more common with older age in all border adults with diabetes $(P<0.001)$ and within the two subgroups $(P<0.001$ for Mexicans and $P=0.066$ for U.S. Hispanics). In both age categories, U.S. Hispanics with diabetes with a smoking history were more likely to be former smokers than were Mexicans, although differences were not statistically significant.

Current smoking was more common among men than women with diabetes in the border population as a whole and in the two border subgroups. Gender differences within both the Mexican and the United States Hispanic populations were significant at $P<0.05$. Mexican men with diabetes were more than twice as likely to be current smokers as their U.S. Hispanic counterparts $(38.9 \%$ versus $15.8 \%, P=$ 0.033). A similar gap was evident among women $(13.3 \%$ versus $5.6 \%, P=0.022)$.
Men with diabetes who smoked consumed more cigarettes per day on average than women for the border population as a whole and for both subgroups, although differences were significant (marginally) only for U.S. Hispanics ( $P=$ 0.070). No significant differences in consumption were evident between the two border groups for either men or women.

Women with diabetes with a smoking history were more likely to have quit than men within both border subgroups ( $P=0.009$ for Mexicans and $P=0.079$ for U.S. Hispanics). The opposite pattern was evident in the region as a whole, although differences were not significant $(P=0.619)$. U.S. Hispanic men were nearly three times as likely to have quit smoking as Mexican men with a smoking history $(50.5 \%$ versus $18.2 \%, P=$ $0.01)$. A difference was also evident for women $(P=0.020)$.

Model 1 in Table 3 confirms that Mexicans with diabetes had substantially higher odds of being a current smoker than U.S. Hispanics (OR 3.15, 95\% confidence interval [CI] 1.45-6.84, $P=0.004$ ). This difference increased and remained significant (Model 2) after controlling for sociodemographic and healthcarerelated characteristics (OR 3.86, 95\% CI 1.50-9.91, $P=0.005)$. Regression analyses adjusting separately for each individual mediator (data not shown) indicate that this increase was due to education and insurance status. Insurance may proxy for higher income in the Mexican border region, which has been found to be positively related to smoking in some areas of Mexico $(34,35)$. Controlling for other sociodemographic characteristics, healthcare access, and border population, men with diabetes in the region were much more likely than women to be current smokers (OR 4.00, 95\% CI 1.89-8.44, $P<0.001)$. Insured adults with diabetes were significantly less likely than the uninsured to be current smokers (OR $0.35,95 \%$ CI $0.14-0.87, P=0.023)$, net of other covariates.

Relative to U.S. Hispanics (Model 1, Table 4), Mexicans with diabetes with a history of smoking had significantly lower odds of being a former smoker (OR 0.23, 95\% CI 0.09-0.56, P = 0.001). Some of this difference (Model 2) was explained by sociodemographic and healthcare-related characteristics, with an increase in the OR to 0.42 (95\% CI 0.16-1.09). Only a marginal difference remained between the two groups ( $P=$ 0.074) after controlling for covariates. Models adjusting individually for each potential mediator (data not shown) suggest that age alone had an explanatory effect on differences in the odds of being a former smoker between the two groups. Similar disparities between Mexicans and U.S. Hispanics were found in a sensitivity analysis where the definition of former smoking was limited to those who were successful quitters (i.e., 
TABLE 2. Smoking behaviors among adults with diabetes residing on the U.S.-Mexico border, U.S.-Mexico Border Diabetes Prevention and Control Project survey, 2001-2002a

\begin{tabular}{|c|c|c|c|c|c|c|c|}
\hline \multirow[b]{2}{*}{ Behavior } & \multicolumn{2}{|c|}{$\begin{array}{l}\text { Borderb }^{b} \\
(n=665)\end{array}$} & \multicolumn{2}{|c|}{$\begin{array}{l}\text { Mexican } \\
(n=333)\end{array}$} & \multicolumn{2}{|c|}{$\begin{array}{l}\text { U.S. } \\
\text { Hispanic } \\
(n=268)\end{array}$} & \multirow[b]{2}{*}{$P^{c}$} \\
\hline & $\%$ & $\mathrm{SE}^{\mathrm{d}}$ & $\%$ & SE & $\%$ & $\overline{\mathrm{SE}}$ & \\
\hline \multicolumn{8}{|c|}{$\begin{array}{l}\text { Current smokers } \\
\text { (among all adults with diabetes) }\end{array}$} \\
\hline \multicolumn{8}{|l|}{ Age specific } \\
\hline 18-54 years & 25.7 & 5.1 & 32.1 & 5.9 & 8.1 & 3.3 & $<0.001$ \\
\hline$\geq 55$ years & 15.8 & 4.4 & 14.8 & 3.5 & 12.0 & 4.7 & 0.644 \\
\hline \multicolumn{8}{|l|}{ Sex } \\
\hline Men & 23.8 & 5.3 & 38.9 & 7.4 & 15.8 & 6.7 & 0.033 \\
\hline Women & 17.1 & 4.1 & 13.3 & 3.1 & 5.6 & 1.8 & 0.022 \\
\hline \multicolumn{8}{|l|}{$\begin{array}{l}\text { Former smokers } \\
\text { (among all adults } \\
\text { with diabetes) }\end{array}$} \\
\hline $\begin{array}{l}\text { All adults } \\
\text { Age specific }\end{array}$ & 22.8 & 3.3 & 10.0 & 1.9 & 16.7 & 4.1 & 0.001 \\
\hline 18-54 years & 4.9 & 1.4 & 6.2 & 2.1 & 4.8 & 2.6 & 0.104 \\
\hline$\geq 55$ years & 40.4 & 1.4 & 17.3 & 3.9 & 27.7 & 6.1 & 0.247 \\
\hline \multicolumn{8}{|l|}{ Sex } \\
\hline Men & 28.9 & 7.5 & 8.7 & 2.7 & 15.6 & 5.7 & 0.012 \\
\hline Women & 16.0 & 3.5 & 11.2 & 2.7 & 17.7 & 5.6 & 0.020 \\
\hline \multicolumn{8}{|c|}{$\begin{array}{l}\text { Former smokers (among } \\
\text { adults with diabetes with } \\
\text { a smoking history) }\end{array}$} \\
\hline Unweighted $n$ & 257 & & 123 & & 89 & & \\
\hline All adults & 52.5 & 7.1 & 27.5 & 5.4 & 62.6 & 8.6 & 0.001 \\
\hline \multicolumn{8}{|l|}{ Age specific } \\
\hline $18-54$ years & 16.1 & 4.6 & 16.2 & 5.5 & 37.2 & 13.7 & 0.104 \\
\hline$\geq 55$ years & 72.0 & 7.9 & 53.9 & 8.1 & 70.1 & 10.3 & 0.235 \\
\hline \multicolumn{8}{|l|}{ Sex } \\
\hline Men & 54.9 & 9.7 & 18.2 & 5.8 & 50.5 & 11.8 & 0.010 \\
\hline Women & 48.3 & 8.9 & 45.8 & 8.6 & 76.4 & 8.6 & 0.020 \\
\hline \multicolumn{8}{|c|}{$\begin{array}{l}\text { Cigarettes smoked per day } \\
\text { (among current } \\
\text { smokers with diabetes) }\end{array}$} \\
\hline \multirow[t]{2}{*}{ Unweighted $n$} & \multicolumn{2}{|c|}{$n=125$} & \multicolumn{2}{|c|}{$n=72$} & \multicolumn{2}{|c|}{$n=33$} & \\
\hline & Mean & SE & Mean & SE & Mean & SE & \\
\hline All adults & 14.1 & 1.9 & 12.3 & 3.4 & 11.7 & 2.4 & 0.892 \\
\hline \multicolumn{8}{|l|}{ Age specific } \\
\hline $18-54$ years & 13.4 & 2.8 & 10.5 & 3.9 & 12.9 & 3.1 & 0.633 \\
\hline$\geq 55$ years & 15.2 & 1.8 & 19.8 & 4.2 & 11.0 & 3.3 & 0.103 \\
\hline \multicolumn{8}{|l|}{ Sex } \\
\hline Men & 15.7 & 2.9 & 13.3 & 4.3 & 13.4 & 3.1 & 0.984 \\
\hline Women & 11.5 & 1.3 & 8.6 & 1.6 & 6.7 & 2.0 & 0.462 \\
\hline
\end{tabular}

a Estimates are weighted using weights provided by the U.S.-Mexico Border Diabetes Prevention and Control Project (29). bIncludes all adults with diabetes on the U.S.-Mexico border, including Mexicans, U.S. Hispanics, non-Hispanic whites, and U.S. adults of other racial or ethnic background.

${ }^{c} P$ value from chi-squared tests (percentages) and least-squares regression (means) for differences in characteristics for U.S. Hispanic versus Mexican adults.

dSE: standard error.

those who quit smoking more than 6 months before the survey; data not shown). Model 2 also indicates that, independent of border population and other covariates, the odds of being a former smoker increased by about $6 \%$ with each year of age (OR 1.06, 95\% CI 1.02-1.11, $P=0.005)$. In addition, men with diabetes with a smoking history were less likely than women to be former smokers (OR 0.21, 95\% CI 0.09-0.50, P < 0.001 ), net of other variables.
No interaction was found between border group and gender for either outcome (data not shown; $P$ for interaction $=0.747$ for current smoking and $P=$ 0.882 for former smoking). However, the association between former smoking and border population varied by diagnosis status ( $P$ for interaction $=0.002)$. The interaction for current smoking was marginally significant $(P=0.057)$. Predicted probabilities suggest that the probability of being a former smoker was higher among diagnosed than undiagnosed U.S. Hispanics with a smoking history $(76.0 \%$ versus $23.7 \%)$. However, there was little difference among Mexicans based on diagnosis (39.1\% for diagnosed versus $41.7 \%$ for undiagnosed). Similarly, U.S. Hispanics with diabetes had a substantially lower probability of being a current smoker if diagnosed $(5.3 \%)$ versus undiagnosed (18.8\%), whereas this probability was slightly higher among diagnosed (20.0\%) than undiagnosed (17.8\%) Mexicans.

\section{DISCUSSION}

In 2001-2002, one in five adults with diabetes residing on the U.S.-Mexico border-an area with a high prevalence of diabetes-was a current smoker. Current smokers with diabetes consumed approximately 14 cigarettes per day. Among those with diabetes who had ever smoked 100 cigarettes or more in their lives, approximately half had quit smoking.

Prevalence of smoking behaviors among all border adults with diabetes masked substantial differences between Hispanics on either side of the border. Mexicans with diabetes were more than twice as likely to be current smokers as their U.S. Hispanic counterparts (26.2\% versus $10.1 \%$ ). While U.S. Hispanics with diabetes were more educated and more likely to be aware of their diabetes status than Mexicans with diabetes, these and other sociodemographic and healthcarerelated characteristics did not explain disparities. Smokers in both groups consumed approximately the same number of cigarettes per day on average. Being a former smoker was much more common among U.S. Hispanics with diabetes with a smoking history than among their Mexican counterparts $(62.6 \%$ versus $27.5 \%$ ). This gap was explained in part by younger age among Mexicans. The prevalence of current smoking in each group was lower than estimates from national surveys from the United States and Mexico conducted during approximately the same time period $(18,19)$. While prevalence estimates across surveys are not strictly comparable, these studies found that $18.9 \%$ of U.S. Hispanics with diabetes (versus $10.1 \%$ found in this study) and $34.0 \%$ of Mexicans with diabetes (versus $26.2 \%$ in this study) were current smokers $(18,19)$. Research that explores differences and sources of 
TABLE 3. Odds ratios (OR) for current smoking among Mexican and U.S. Hispanic adults with diabetes residing on the U.S.-Mexico border, U.S.-Mexico Border Diabetes Prevention and Control Project survey, 2001-2002 $(n=601)$

\begin{tabular}{|c|c|c|c|c|}
\hline & \multicolumn{2}{|c|}{ Model 1} & \multicolumn{2}{|c|}{ Model 2} \\
\hline & OR & $95 \% \mathrm{Cl}^{\mathrm{a}}$ & OR & $95 \% \mathrm{Cl}$ \\
\hline Mexican (ref:b U.S. Hispanic) & 3.15 & $1.45-6.84$ & 3.86 & $1.50-9.91$ \\
\hline Age & & & 1.00 & $0.98-1.03$ \\
\hline Men (ref: women) & & & 4.00 & $1.89-8.44$ \\
\hline High school or more (ref: less than high school) & & & 1.71 & $0.73-3.99$ \\
\hline Married or consensual union (ref: unmarried) & & & 0.70 & $0.32-1.51$ \\
\hline Diagnosed with diabetes (ref: undiagnosed) & & & 0.74 & $0.30-1.82$ \\
\hline Insured (ref: not insured) & & & 0.35 & $0.14-0.87$ \\
\hline \multirow{2}{*}{$\begin{array}{l}\text { Visited healthcare professional in last } 12 \text { months } \\
\text { (ref: did not visit) }\end{array}$} & & & & \\
\hline & & & 1.43 & $0.53-3.87$ \\
\hline
\end{tabular}

${ }^{\mathrm{a}} \mathrm{Cl}$ : confidence interval.

b ref: reference group.

TABLE 4. Odds ratios (OR) for former smoking among Mexican and U.S. Hispanic adults with diabetes with a smoking history, U.S.-Mexico Border Diabetes Prevention and Control Project survey, 2001-2002 $(n=212)$

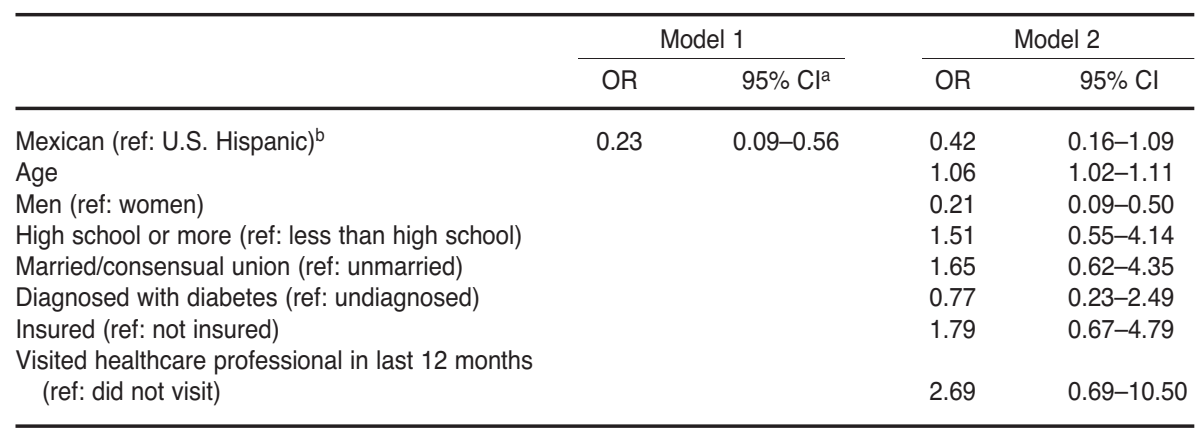

${ }^{\mathrm{a}} \mathrm{Cl}$ : confidence interval.

b ref: reference group.

variation in smoking prevalence among adults with diabetes in the border region relative to the general population or to populations with diabetes in other regions may be helpful to smoking prevention and cessation efforts in each country.

Findings further suggest that younger Mexicans ( $<55$ years) with diabetes were at particularly high risk of smoking. Smoking prevalence was four times higher in younger Mexicans ( $<55$ years) with diabetes than in their U.S. Hispanic counterparts. There was no significant difference in smoking prevalence between those aged $\geq 55$ years between the two border groups. These results suggest that younger Mexican adults with diabetes may be at much higher risk of morbidity and mortality over the life course than younger U.S. Hispanic adults, given the synergistic relationship between smoking and diabetes (36-39). It was further found that younger Mexican adults with diabetes had more than twice the prevalence of smoking as older
Mexican adults. This finding contrasts with those from a nationwide study of Mexicans with diabetes, which found the reverse pattern (18). Results suggest an urgent need for smoking prevention and cessation efforts among younger Mexican adults with diabetes in the region.

The reasons behind disparities in smoking prevalence by age between the two border groups is an important topic for future investigation. Previous research has suggested that contextual determinants may lower smoking rates in the Mexican-origin population in the United States relative to their Mexican counterparts $(13,40)$. In particular, the regulatory environment surrounding smoking in the United States is more restrictive than in Mexico and has been for some time. These policies may have discouraged smoking uptake among younger U.S. Hispanics to a greater extent than among younger Mexicans. Mexico, for instance, has only recently begun to enact key antismoking restrictions and has low levels of enforcement of regula- tions concerning sales of cigarettes to minors $(12,14,15)$. Moreover, taxation of tobacco, relative to price, is significantly lower in Mexico than in the United States (16). Cigarettes, whether due to more limited taxation or industry pricing, were cheaper in Mexico than in the United States at the time of the survey (41). Pricerelated policies have been found to be important in determining smoking among younger individuals, particularly in adolescence (42-44). In addition, available resources and capacity for communitybased tobacco intervention and mass media public education campaigns, many of which may target younger individuals, were likely to have differed substantially in the two border regions at the time of the survey (45). Differences in smoking policies may thus lie behind the disparities among younger Mexicans versus U.S. Hispanics with diabetes. These disparities may even out with age, in that differences were not evident among older populations with diabetes; alternatively, this may indicate a cohort effect of tobaccorelated policies in the two countries.

Men with diabetes in the region were a second at-risk group in terms of current and former smoking. Regardless of area of border residence, men with diabetes were more likely to be current smokers than women in the region, consumed more cigarettes per day, and were less likely to be former smokers among those with a smoking history. These findings are consistent with patterns found in national studies of men and women with diabetes in the United States (19). Higher levels of smoking among men than women in the largely Hispanic border population with diabetes may be linked to gender differences concerning perceived acceptability of smoking (25-27).

Mexican men with diabetes were particularly at risk, with nearly three times the rate of current smoking as U.S. Hispanic men. Mexican men (18.2\%) were also far less likely to be former smokers, among adults with diabetes with a smoking history, than were U.S. Hispanic men (50.5\%). Large gaps were also evident for both current and former smoking between Mexican and U.S. Hispanic women. There was no interaction between border population and gender, providing little evidence that gender norms surrounding smoking behaviors are stronger in Mexico than in the U.S. border region among Hispanics. Gaps 
in smoking behaviors between gender groups with diabetes in the two populations-as well as those in the overall U.S. versus Mexican border populations with diabetes-may be due to the more restrictive regulatory environment surrounding smoking in the United States versus Mexico. For example, Mexico only recently passed clean indoor air laws and began to restrict smoking advertising (14). It had less regulation of smoking in the workplace and less enforcement of existing workplace smoking bans than was the case in the United States $(12,14)$. The much higher prevalence of current smoking among Mexican than U.S. Hispanic men with diabetes, combined with their lower prevalence of former smoking, suggests that they are an important target group for smoking prevention and cessation efforts.

Healthcare also factored into disparities in smoking behaviors between the two border populations in important ways. With regard to diabetes diagnosis, being a former smoker was much more likely among diagnosed than undiagnosed U.S. Hispanics with a smoking history than was the case for Mexicans. Results for U.S. Hispanics are consistent with prior research in the United States, which has shown that smoking cessation is associated with a diagnosis of diabetes $(21,46)$. Less is known about this association in Mexico; however, this analysis suggests that diagnosis has little impact on smoking cessation among Mexicans with diabetes who smoke in the border region. U.S. Hispanic smokers, in contrast, may be receiving effective counseling for smoking cessation at and after diagnosis in healthcare settings. Findings suggest that there is a need to improve smoking cessation counseling in connection with diagnosis of diabetes in the Mexican healthcare system in the border area. Moreover, having health insurance was independently associated with a lower likelihood of being a current smoker in the border population in general. This suggests that increasing access to health insurance may reduce smoking prevalence among adults with diabetes in the region.

Due to limited data availability, it was not possible to investigate other smokingrelated factors that may differentiate health risks between Mexicans and U.S. Hispanics with diabetes in the border region, such as being an every day versus some days smoker, age at initiation, tar and nicotine content of cigarettes, and behaviors such as degree of inhalation $(47,48)$. These factors may be important in assessing differential cumulative risk of smoking for adults with diabetes and in designing interventions. Because sample size was limited, it was not possible to analyze smoking cessation efforts and successful quitting during the course of diabetes. In the analysis, some former smokers were likely to have quit before developing diabetes or before learning of their diabetes status. Also, due to sample size, it was not possible to examine smoking behaviors among U.S. Hispanic subgroups by acculturation in multivariate analyses; however, in unadjusted analyses, no differences were found in the likelihood of smoking behaviors for U.S.-born versus foreign-born Hispanics on the U.S. side of the border. In addition, each smoking behavior was based on self-reports. Misreporting of smoking is generally low in Hispanic populations but has been found to vary by acculturation and so may have influenced results (49). Data were collected in 2002; additional research is needed to determine whether disparities in smoking behaviors in border populations have shifted since the time of the survey.

Despite these limitations, the study had significant strengths. The data pro- vided the opportunity to examine smoking behaviors among adults with diabetes in a region with high diabetes prevalence and among subgroups with similar cultural backgrounds residing in contexts with distinct tobacco control policies. As a result, it was possible to identify important differences and similarities in smoking behaviors between border subgroups, to make recommendations for targeting prevention and cessation efforts, and to identify promising areas for future research.

Smoking prevention and cessation efforts are essential among adults with diabetes, given the risks of smoking for diabetes complications and mortality. Smoking behaviors in the Mexican border population with diabetes represent a particular cause for concern, especially among younger Mexican adults and Mexican men. Smoking prevention and intervention represent a potentially important avenue for preventing diabetes complications and associated costs in these populations and in the regional population as a whole. Efforts to improve smoking prevention and cessation counseling at and after diabetes diagnosis in the Mexican border healthcare system may be particularly important in improving health in the border population.

Acknowledgments. P.S. was supported in this research by a postdoctoral fellowship from the Philip R. Lee Institute for Health Policy Studies, University of California, San Francisco, School of Medicine. G.H. was funded by Centers for Disease Control and Prevention grant 1U58DP002007-01. D.S. was funded by National Institutes of Health grant ULRR02413. The authors acknowledge the use of data for this study provided by the Pan American Health Organization/World Health Organization U.S.-Mexico Border Office.

\section{REFERENCES}

1. World Health Organization. WHO report on the global tobacco epidemic 2009: implementing smoke-free environments. Geneva: WHO; 2009.

2. Chuahirun T, Simoni J, Hudson C, Seipel T, Khanna A, Harrist RB, et al. Cigarette smoking exacerbates and its cessation ameliorates renal injury in type 2 diabetes. Am J Med Sci. 2004;327(2):57-67.

3. Gambaro G, Bax G, Fusaro M, Normanno M, Manani SM, Zanella M, et al. Cigarette smok- ing is a risk factor for nephropathy and its progression in type 2 diabetes mellitus. Diabetes Nutr Metab. 2001;14(6):337-42.

4. Nilsson PM, Gudbjornsdottir S, Eliasson B, Cederholm J. Smoking is associated with increased $\mathrm{HbA} 1 \mathrm{c}$ values and microalbuminuria in patients with diabetes-data from the $\mathrm{Na}$ tional Diabetes Register in Sweden. Diabetes Metab. 2004;30(3):261-8.

5. Fagard RH. Smoking amplifies cardiovascular risk in patients with hypertension and diabetes. Diabetes Care. 2009;32(2 supl): S429-31.

6. Karim R, Buchanan TA, Hodis HN, Li Y, Mack WJ. The association of smoking and subclinical atherosclerosis in type 2 diabetes: modification by duration of diabetes. Diabet Med. 2005;22(1):81-7.

7. Al-Delaimy WK, Manson JE, Solomon CG, Kawachi I, Stampfer MJ, Willett WC, et al. Smoking and risk of coronary heart disease among women with type 2 diabetes 
mellitus. Arch Intern Med. 2002;162(3): 273-9.

8. Al-Delaimy WK, Willett WC, Manson JE, Speizer FE, Hu FB. Smoking and mortality among women with type 2 diabetes: The Nurses' Health Study cohort. Diabetes Care. 2001;24(12):2043-8.

9. Pan American Health Organization. The US-Mexico Border Diabetes Prevention and Control Project. First report of results. Washington, D.C.: PAHO; 2005.

10. Olaiz-Fernández G, Rojas R, Aguilar-Salinas CA, Rauda J, Villalpando S. Diabetes mellitus en adultos mexicanos. Resultados de la Encuesta Nacional de Salud 2000. Salud Publica Mex. 2007;49:s331-7.

11. Cowie CC, Rust KF, Byrd-Holt DD, Eberhardt MS, Flegal KM, Engelgau MM, et al. Prevalence of diabetes and impaired fasting glucose in adults in the U.S. population: National Health and Nutrition Examination Survey 1999-2002. Diabetes Care. 2006;29(6):1263-8.

12. Martínez-Donate AP, Hovell MF, Hofstetter CR, González-Pérez GJ, Adams MA, Sánchez J, et al. Smoking, exposure to secondhand smoke, and smoking restrictions in Tijuana, Mexico. Rev Panam Salud Publica. 2005;18(6): 412-7.

13. Martínez-Donate AP, Hovell MF, Hofstetter CR, González-Pérez GJ, Kotay A, Adams MA. Crossing borders: the impact of the California Tobacco Control Program on both sides of the US-Mexico Border. Am J Public Health. 2008; 98(2):258-67.

14. Valdés-Salgado R, Lazcano-Ponce EC, Hernández-Ávila M. Current panorama of tobacco consumption and control measures in Mexico. Prev Control. 2005;1(4):319-27.

15. Adame-Moreno R, Ibarra-Heredia O, TorresSimental H. Illegal sales of cigarettes to minors-Ciudad Juarez, Mexico; El Paso, Texas; and Las Cruces, New Mexico, 1999. MMWR Morb Mortal Wkly Rep. 1999;48(19):394-8.

16. Jiménez-Ruiz JA, de Miera BS, ReynalesShigematsu LM, Waters HR, HernándezÁvila M. The impact of taxation on tobacco consumption in Mexico. Tob Control. 2008; 17(2):105-10.

17. Kuri-Morales P, Cravioto P, Hoy MI, TapiaConyer R. Assessment of cigarette sales to minors in Mexico. Tob Control. 2000;9(4):436-7.

18. Aguilar-Salinas CA, Monroy OV, GómezPérez FJ, Chávez AG, Esqueda AL, Cuevas VM, et al. Characteristics of patients with type 2 diabetes in Mexico: results from a large population-based nationwide survey. Diabetes Care. 2003;26(7):2021-6.

19. Ford ES, Mokdad AH, Gregg EW. Trends in cigarette smoking among US adults with diabetes: findings from the Behavioral Risk Factor Surveillance System. Prev Med. 2004; 39(6):1238-42.

20. Lee C, Kahende J. Factors associated with successful smoking cessation in the United States, 2000. Am J Public Health. 2007;97(8): 1503-9.

21. Keenan PS. Smoking and weight change after new health diagnoses in older adults. Arch Intern Med. 2009;169(3):237-42.
22. Barbeau EM, Krieger N, Soobader M-J. Working class matters: socioeconomic disadvantage, race/ethnicity, gender, and smoking in NHIS 2000. Am J Public Health. 2004:94(2): 269-78.

23. Kuri-Morales P, González-Roldán J, Hoy M, Cortés-Ramírez M. Epidemiología del tabaquismo en México. Salud Publica Mex. 2006; 48(1 supl):s91-8.

24. Anonymous. Smoking-ban bill approved in Mexico. The Los Angeles Times. 27 February 2008;A.9.

25. Abraído-Lanza AF, Chao MT, Flórez KR. Do healthy behaviors decline with greater acculturation? Implications for the Latino mortality paradox. Soc Sci Med. 2005;61(6):1243-55.

26. Acevedo-Garcia D, Bates L. Latino health paradoxes: empirical evidence, explanations, future research, and implications. In: Rodríguez $H$, Sáenz R, Menjívar C, eds. Latinas/os in the United States: changing the face of América. New York: Springer US; 2008. Pp. 101-3.

27. Foraker RE, Patten CA, Lopez KN, Croghan IT, Thomas JL. Beliefs and attitudes regarding smoking among young adult Latinos: a pilot study. Prev Med. 2005;41(1):126-33.

28. Frenk J, González-Pier E, Gómez-Dantés O, Lezana MA, Knaul FM. Reforma integral para mejorar el desempeño del sistema de salud en México. Salud Publica Mex. 2007;49:s23-36.

29. The US-Mexico Border Diabetes Project. Operations manual. Washington, D.C.: PAHO; 2001.

30. de Cosío FG, Díaz-Apodaca BA, RuizHolguín R, Lara A, Castillo-Salgado C. United States-Mexico Border Diabetes Prevalence Survey: lessons learned from implementation of the project. Rev Panam Salud Publica. 2010;28(3):151-8.

31. Fagan P, Shavers VL, Lawrence D, Gibson JT, O'Connell ME. Employment characteristics and socioeconomic factors associated with disparities in smoking abstinence and former smoking among U.S. workers. J Health Care Poor Underserved. 2007;18(4 suppl): 52-72.

32. Guzmán B. The Hispanic population: census 2000 brief. Washington, D.C.: U.S. Census Bureau; 2001.

33. StataCorp. Stata Statistical Software. Release 11.0. College Station, Texas: Stata Corporation; 2009.

34. Buttenheim AM, Wong R, Goldman N, Pebley AR. Does social status predict adult smoking and obesity? Results from the 2000 Mexican National Health Survey. Glob Public Health. 2009:1-14.

35. Smith K, Goldman N. Socioeconomic differences in health among older adults in Mexico. Soc Sci Med. 2007;65(7):1372-85.

36. Chaturvedi N, Stephenson JM, Fuller JH. The relationship between smoking and microvascular complications in the EURODIAB IDDM Complications Study. Diabetes Care. 1995;18 (6):785-92.

37. Targher $\mathrm{G}$, Alberiche $\mathrm{M}$, Zenere MB, Bonadonna RC, Muggeo M, Bonora E. Cigarette smoking and insulin resistance in patients with noninsulin-dependent diabetes mellitus. J Clin Endocrinol Metab. 1997;82 (11): 3619-24.

38. Fagard RH, Nilsson PM. Smoking and diabetes-the double health hazard! Prim Care Diabetes. 2009;3(4):205-9.

39. Chaturvedi N, Stevens L, Fuller JH. Which features of smoking determine mortality risk in former cigarette smokers with diabetes? The World Health Organization Multinational Study Group. Diabetes Care. 1997;20 (8):1266-72.

40. Stoddard P. Risk of smoking initiation among Mexican immigrants before and after immigration to the United States. Soc Sci Med. 2009;69(1):94-100.

41. Guindon GE, Tobin S, Yach D. Trends and affordability of cigarette prices: ample room for tax increases and related health gains. Tob Control. 2002:11(1):35-43.

42. Botello-Harbaum MT, Haynie DL, Iannotti RJ, Wang J, Gase L, Simons-Morton B. Tobacco control policy and adolescent cigarette smoking status in the United States. Nicotine Tob Res. 2009;11(7):875-85.

43. Carpenter C, Cook PJ. Cigarette taxes and youth smoking: new evidence from national, state, and local Youth Risk Behavior Surveys. J Health Econ. 2008;27(2):287-99.

44. Tworek C, Yamaguchi R, Kloska DD, Emery S, Barker DC, Giovino GA, et al. State-level tobacco control policies and youth smoking cessation measures. Health Policy. 2010;97 (2-3):136-44.

45. Lantz PM, Jacobson PD, Warner KE, Wasserman J, Pollack HA, Berson J, et al. Investing in youth tobacco control: a review of smoking prevention and control strategies. Tob Control. 2000;9(1):47-63.

46. Twardella D, Loew M, Rothenbacher D, Stegmaier C, Ziegler H, Brenner H. The diagnosis of a smoking-related disease is a prominent trigger for smoking cessation in a retrospective cohort study. J Clin Epidemiol. 2006; 59(1):82-9.

47. Peto R. Influence of dose and duration of smoking on lung cancer rates. In: Zaridze D, Peto R, eds. Tobacco: a major international health hazard. Lyon: International Agency for Research on Cancer; 1986. Pp. 23-33. (IARC Scientific Publications No. 74.)

48. Ezzati M, Lopez AD. Estimates of global mortality attributable to smoking in 2000 . Lancet. 2003;362(9387):847-52

49. Everhart J, Ferketich AK, Browning K, Wewers ME. Acculturation and misclassification of tobacco use status among Hispanic men and women in the United States. Nicotine Tob Res. 2009;11(3):240-7.

Manuscript received on 22 March 2010. Revised version accepted for publication on 7 September 2010 
RESUMEN Objetivo. Analizar la prevalencia de tabaquismo en adultos con diabetes residentes en la zona fronteriza entre los Estados Unidos y México, comparar este hábito entre los hispanos estadounidenses y los mexicanos con diabetes, y tratar de explicar las

\section{Hábito tabáquico en adultos hispanos con diabetes residentes en la frontera México-Estados Unidos: una oportunidad de salud pública} diferencias observadas entre ambos grupos.

Métodos. Los datos procedieron de la encuesta del Proyecto de Prevención y Control de la Diabetes en la Frontera México-Estados Unidos (2001-2002), llevada a cabo en una muestra estratificada polietápica, representativa de la población fronteriza. La muestra analítica incluyó a adultos con diabetes de todos los orígenes raciales y étni$\cos (n=665)$, incluidos 333 mexicanos y 268 hispanos estadounidenses. La información en cuanto al hábito de fumar fue facilitada por los entrevistados. Se calculó la prevalencia específica de tabaquismo según sexo y edad, y se llevó a cabo el análisis de mediación de las diferencias entre grupos mediante regresión logística.

Resultados. En el momento de la encuesta, uno de cada cinco $(20,1 \%)$ adultos con diabetes de la región era fumador. La prevalencia fue mayor entre los mexicanos $(26,2 \%)$ que entre los hispanos estadounidenses $(10,1 \%, P=0,003)$; estas diferencias no se pudieron explicar por las características sociodemográficas o las relacionadas con la atención de salud (razón de posibilidades [OR] 3,86, intervalo de confianza [IC] de $95 \% 1,50-9,91, P=0,004)$. La probabilidad de que los mexicanos más jóvenes con diabetes (menores de 55 años) fueran fumadores fue cuatro veces mayor que la de los estadounidenses hispanos más jóvenes $(32,1 \%$ frente a $8,1 \%, P<0,001)$. La probabilidad de que los varones mexicanos con diabetes fumaran fue más del doble que la de los varones hispanos estadounidenses (38,9\% frente a 15,8\%, $P=0,003)$. Entre los adultos con diabetes que tenían antecedentes de tabaquismo, 52,5\% eran ex fumadores; la probabilidad de que los hispanos estadounidenses con diabetes fueran ex fumadores resultó mayor que la de los mexicanos con diabetes $(62,6 \%$ frente a $27,5 \%, P=0,001)$. Tras el ajuste por mediadores potenciales se mantuvo una diferencia marginalmente significativa (OR 0,42, IC 95\% 0,17-1,08, $P=0,074$ ).

Conclusiones. Las intervenciones en materia de tabaquismo en la zona fronteriza deben centrarse en los mexicanos con diabetes, especialmente en los varones jóvenes y adultos. La determinación de las causas que ocasionan las diferencias en el hábito de fumar entre los grupos fronterizos de personas con diabetes puede aportar nuevos datos útiles para futuras intervenciones.

Palabras clave Tabaco; tabaquismo; cese del tabaquismo; salud fronteriza; hispanoamericanos; México. 